\title{
Ergativity and Change in Inuktitut ${ }^{\circ}$
}

\author{
Alana Johns, Department of Linguistics \\ University of Toronto
}

\section{Introduction}

Ergativity is property of a language which treats the subject of an intransitive verb as identical in some grammatical fashion to the patient/theme argument of a transitive verb. Explanations for this patterning within generative grammar are many (see Manning 1996; Johns 2000 for an overview). It is also known that languages can change from nominative-accusative to ergative and vice-versa (see Dixon 1994). In light of accounts in generative grammar where ergativity is not a single property within universal grammar, e.g. Johns (1992); Bittner and Hale (1996a; 1996b), we expect that changes in ergativity will also vary, restricted by universal grammar. At the same time we expect that these changes will shed light on the overall nature of ergativity, as linguistic change highlights critical subsets of properties of a grammar. In this paper we will examine one language, Inuktitut, which has undergone a partial change, observable across dialects. As outlined in Johns (1999), ergative patterning is more predominant in Inuktitut dialects spoken in the west in than the more easterly dialects, especially Labrador Inuttut. In this paper we will examine in detail one aspect of that change, the properties of the antipassive construction. Johns (2001a; 2001b) argues that it is properties of the

\footnotetext{
- Thanks to all the participants at the Ergativity Workshop held in Toronto 2002. Thanks also to my fellow organizers Diane Massam and Juvenal Ndayiragije. I would also like to thank Susana Bejar and Bettina Spreng for helpful discussion. This paper was supported by SSHRC Aid to Research Workshops and Conferences in Canada and by SSHRC Standard Research Grant \#410030887.
} 
antipassive construction, not the ergative construction, which have led the change in eastern dialects and are thus the focal point of ergativity change in Inuktitut. ${ }^{1}$ In this paper we will examine formal properties of that construction in an effort to further understand both the antipassive construction itself and the cross-dialectal change in ergativity.

Central to this question are the properties of both the antipassive morpheme and the case assigned to the object of the antipassive. We will follow Spreng (2001) who proposes that the antipassive morpheme is in little v. I will argue here that antipassive morphemes are in some sense "grammaticalized" aspect, i.e. they contain aspectual features which have a different interpretation when they are merged in little $\mathrm{v}$ from the interpretation they have outside of little $\mathrm{v}$ (see Travis forthcoming for a detailed examination of aspect and object positions crosslinguistically). In addition, we will see that the case on the objects of antipassives has undergone a change across dialects of Inuktitut. Whereas in conservative western dialects, this case is linked to the aspectual features of the antipassive's little $v$, in eastern dialects, it is linked only to the category of little v. As a result, antipassive in western dialects resembles languages like Finnish, where object case shares interpretive features with aspect, while the antipassive in eastern dialects resembles the more familiar accusative pattern. A correlate of this dialectal difference is that ergativity in western dialects is still very robust, while in eastern dialects, it is waning.

\footnotetext{
${ }^{1}$ We may wonder if languages which are becoming less ergative will always show changes in the competing (antipassive) construction, or whether it is in fact possible that a language could become less ergative through changes in the ergative clause itself. At the same time, we may ask whether in languages which are becoming more ergative, the
} 


\section{Ergative vs. Antipassive}

Languages which are described as having ergativity usually have two competing constructions (excluding passive) which allow both the agent and the theme/patient to be expressed. I will call the clause which displays the marked agent the ergative clause. In many instances the competing construction is called the antipassive, a term which traditionally denotes a clause where the agent in subject position, the verb is a derived intransitive, and the object is marked with oblique case. We can see the two constructions in the Inuktitut examples ${ }^{2}$ in (1). ${ }^{3}$

(1) a. anguti-up nanuq kapi-jaa [Ergative construction] man-rel. polar.bear(abs) stab-3s/3s 'The man stabbed the polar bear.'

b. angut pisuk-tuq [Intransitive construction] $\operatorname{man}(\mathrm{abs}) \quad$ walk-3s 'The man is walking.'

locus of the change will be the ergative clause itself (see Dixon 1994 for some discussion). In other words, is it the "usurping" construction which changes? ${ }^{2}$ Abbreviations used in examples, including those from other sources, are: rel.=relative; (abs)=absolutive (phonologically null); $\mathrm{s}=$ singular; $3=$ third person; $1=1^{\text {st }}$ person; /=combined person inflection, i.e. agent and patient/theme; $\mathrm{AP}=$ antipassive; prog=progressive; loc.=locative; Refl=reflexive; V=verb; gen=genitive; DIR=direct (accusative) case; pres=present; erg=ergative; incept=inceptive; intr.=intransitive; mid=middle; act=activity; sub=subject; fut=future; obl=oblique; det=determiner; comp $=$ complementier; aux=auxiliary

${ }^{3}$ In this paper I am simplifying the labelling of mood, transitivity and inflection labeling to just the person and number involved. 
c. angut nanur-mik kapi-si-juq [Antipassive construction]

man(abs) polar.bear-MIK stab-AP-.3s

'The man is stabbing the polar bear.'

In (1a) we see an Ergative construction, where the agent of the clause is in a special case (relative), contrasting with the absolutive case appearing on both the patient/theme of the ergative construction in (1a), and the subject of the intransitive construction in (1b).

Absolutive case is the case which is obligatorily assigned in any Inuktitut clause, although because it is a pro-drop language, this restriction is not always visible. The verb in (1a) also carries agreement features for both subject and object, while in the intransitive example in (1b) there are only features for the agent.

In the antipassive construction in (1c), we see that the agent is in absolutive case, and is the only argument controlling agreement on the verb. Agreement with a single argument is sometimes misleadingly termed intransitive since the agreement system contrasts single and double agreement. Thus single agreement is sometimes called intransitive, and double agreement transitive. Note, however, that were the ergative clause not available for comparison, the single agreement patterns exactly the same as a transitive in a familiar nominative-accusative language, where only agreement with the subject is possible. The theme/patient nanuq 'polar bear' in (1c) is marked with the case morpheme MIK, which is variously called accusative, modalis, instrumental, etc. in the literature.

The derivation of the theme/patient in an antipassive in Inuktitut has been the subject of much study over the last decade (Bok Bennema 1991; Bittner 1987; Bittner and Hale 1996a, 1996b; de Hoop 2003 (and references therein); Benua 1995; Van 
Geenhoven 1998; Spreng 2001 and this volume; Wharram 2003; Beach 2003). It is beyond the scope of the present paper to adequately deal with all the issues arising from this discussion, but I will focus on a few of them as they relate to the language change. Overall, most of the linguists above have concluded that the theme argument of an antipassive is in fact an object argument and not an oblique argument. The choice of the antipassive over the ergative construction has been attributed to scope, indefiniteness, aspect, choice-functions, etc. In this paper, we attempt to focus on this issue as it pertains to language change. The main thing to keep in mind is that, in principle, a patient/theme in Inuktitut in Inuktitut can appear either in absolutive case in the ergative construction or in MIK case in the antipassive construction. This paper is concerned with the formal representation of deviations from this gross generalization. Specifically I will be concerned with dialectal differences associated with the MIK case.

\section{Ergative Change in Inuktitut - an Overview}

Johns (1999) outlines the differences in the role of the ergative clause across dialects of Inuktitut, making the claim that ergativity diminishes in prominence from western to eastern dialects. For the sake of brevity, I will make an artificial binary distinction by contrasting one western dialect of Inuktitut, Iñupiaq, with one easterly dialect, Labrador Inuttut. In fact, the situation is probably a lot more complex, with dialects forming a continuum of change.

The overall impression is that the ergative clause is much more unmarked in the Iñupiaq, while the antipassive is slightly more marked. In contrast Labrador Inuttut uses the antipassive much extensively, and the ergative clause is more rare. 
Providing empirical support for this claim is challenging. Johns (1999; 2001a) discusses a restriction which holds of ergative clauses in Iñupiaq but not in Labrador Inuttut. This is the fact that Iñupiaq does not allow the theme/patient of an antipassive clause to be a name (Manning 1996). ${ }^{4}$ Examples contrasting this distinction between Iñupiaq and Labrador Inuttut in are in (2), where the names are bolded.

(2) a. *John tautuk-tuq Mary-mik

John(abs) see-3s. Mary-MIK

'John sees Mary' b. Margarita

Kuinatsa-i-juk Ritsati-mik

Margarita(abs) tickle-AP-.3s Richard-MIK

'Margarita is tickling Richard'

c. Nancy

angka-li-mmat

Nancy(abs) home-prog.-because.3s
aklâ-gulak
iksiva-juk
Kaksi-tâ-gula-ngmi,
black.bear-dear(abs)
sitting-3s

Iñupiaq [ex. 137 Manning 1996, 95]

\footnotetext{
${ }^{4}$ Seiler (1978) gives an example from Iñupiaq which appear to be violation of this generalization.

i. John uqaq-tuq Mary-mik

John speak-intr.3s Mary-MIK

'John talks about Mary'
} 


\section{iksiva-ju Kaksi-tâ-gula-ngmi Nancy-mi tautuk-tuk.}

sitting-3s. $\quad$ hillock-get-dear-loc.s. Nancy-MIK. look.at-.3s

'... if Nancy was coming home, the young black bear would be sitting on a little hill, sitting on the little hill, watching Nancy'

The source of the ungrammatical example in (2a) is Edna MacLean, an Iñupiaq linguist and speaker of the language. According to Manning (1996), the status of names in antipassive in central dialects Inuktitut is also of some doubt. I have found a similar restriction as that shown in (2a) in Inuvialuktun (Siglitun), a western dialect immediately to the east of Iñupiaq. In Lowe's 1985 grammar of Uummarmiut, a variety of Iñupiaq, there are no names in the numerous examples which contain nominals in MIK case. ${ }^{5}$

The examples in (2b) and (2c), on the other hand, are both from Labrador Inuttut and are perfectly grammatical and common constructions within this dialect. ${ }^{6}$ All three examples are roughly equivalent in verb type and structure, ${ }^{7}$ yet the grammaticality of a name in MIK case within the antipassive is very different.

Johns (1999) hypothesizes that a dialect which loosens restrictions on the antipassive, at the same time tightening restrictions on the ergative clause, will show an increase in

However notice that 'Mary' here is not a referential entity but more of a general topic. This is exactly what we will see predicted under the account given in section 4 for western dialects.

${ }^{5}$ Names can be found in MIK case with an instrumental interpretation. See section 5.1.

${ }^{6}$ The second example is from Rigolet Inuttut, a closely related dialect. There are no differences in ergativity between these two dialects to the best of my knowledge.

${ }^{7}$ This is very important because, as Michael Fortescue informed Manning (1996, 94), a name can exceptionally be found as the theme in an antipassive construction only in 
the number of antipassive clauses. Johns (2001a) investigates this hypothesis by comparing narratives from a number of dialects. The number of tokens of NPs marked with MIK in a Labrador Inuttut narrative is compared with the number obtained from some narratives of western dialects, including Inuvialuktun, which, as mentioned above, is a dialect which prohibits names in antipassives. The point of comparison was simply number of nominals marked with singular MIK case (excluding plural NIK). As it turned out, there was no significant quantitative difference in the frequency of MIK use across the dialects. A closer inspection of the data showed that the frequency of MIK in Inuvialuktun can be explained by this dialect's more frequent use of ditransitive and applicative constructions (less common in eastern dialects). These constructions make use of MIK as an extra case. As only one absolutive case is ever available, and absolutive is normally associated with the goal or beneficiary in ditransitives and applicatives, the theme/patient will be marked with MIK. An example from Iñupiaq is given in (3). where the goal irñi-ni 'his son' is associated with absolutive case and agreement on the verb, and the theme huppun 'gun' appears with MIK case.

$\begin{array}{clll}\text { (3) huppun-mik } & \text { irñi-ni } & \text { aatchu-raa } & \text { [Lowe 1985a, 61] } \\ \text { gun-MIK } & \text { son-Refl3s } & \text { give-3s/3s }\end{array}$

'He gave his son a gun'

Thus the overall consistency in the percentage of MIK use across dialects does not reflect similarity in use of antipassive, but instead the interesting fact that as the number of ditransitives and applicatives diminishes, the number of antipassives increases.

syntactic contexts where the ergative clause is not permitted for independent reasons, e.g. when a relative clause has an agent as head. See also Dixon $(1994,195)$. 
In summary, we have seen that there is reason to believe that western dialects differ from eastern dialects in terms of markedness of the antipassive construction. In western dialects, the ergative is the unmarked choice for a transitive construction, with the antipassive being somewhat marked. Ditransitives and applicatives are common. In contrast, in eastern dialects, the antipassive is quite unmarked, and the status of the ergative in these instances is minimally marginalized. Ditransitives and applicatives are less common. ${ }^{8}$ These generalizations apply specifically to third person agent/ third person patient/theme combinations. Whether other person combinations show the same distribution is unclear at this time and requires further investigation. ${ }^{9}$

It is important to keep in mind that the MIK case is not found exclusively in the antipassive construction. It is also found in a) instrumental case in the western dialects (see section 5.1), b) ditransitives and applicatives, as discussed above, and c) modifiers of incorporated nouns. When an incorporated noun has any additional material which is outside the root, it must appear adjacent to the nominal root in MIK case, as in (4)
(4) qatiqu-mik
atigi-ruaq-tuaq
Inuvialuktun [Lowe 1985b, 65]
white-MIK parka-have-3s
'He has a white parka'

\section{The Components of the Antipassive: (Verbal Affix) + Case}

The antipassive in Inuktitut consists of i. an "intransitive verb" i.e. a verb with single agreement, ii. sometimes an antipassive affix, plus iii. the theme/patient in MIK case. We

\footnotetext{
${ }^{8}$ In fact, it may be the case that these are more frequently found with non-transitive inflection in Labrador Inuttut. This possibility needs more research.
} 
will consider each of these components in turn because, as we will see, each occurs independently of the antipassive construction. It is only when they co-occur that we get the constellation of properties which we call antipassive.

\subsection{Nature of the MIK case.}

Given the wide range of usages of the MIK case throughout Inuktitut, as discussed above in section 2, I will argue that MIK is the default structural case in Inuktitut. A default case is, according to Schütze (2001), a default spell-out of on DPs which are independently licensed in the syntax. As such, we do not expect it to be associated with any one syntactic configuration. de Hoop (2003) finds support for Vainikkaa (1989), who proposes that the Finnish partitive case is a structural default case in Finnish. We will see that the Finnish partitive has some resemblance to the MIK case, as has been noted by de Hoop (2003) and Benua (1995; 2001), and others.

In Johns (2001b) I propose that the structure of the MIK case is a light or little k, which takes a nominal complement. This is shown in (5).

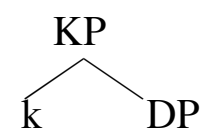

Under this view, the MIK case is a functional element. Like little $\mathrm{v}$ in VPs, the little $\mathrm{k}$ may contain features.

Johns (2003) and Compton (2004) propose that all Inuktitut nominals are referential (see also Wharram 2003, who claims they are non-quantificational), and therefore do not need independent determiners. This claim has wider implications than

\footnotetext{
${ }^{9}$ For speakers of some South Baffin dialects, the use of the ergative is prohibited only
} 
space permits here. This claim predicts that a bare nominal cannot receive a kind or set interpretation without some additional morphology, such as that which is sometimes mediated by MIK.

As a default case, little $\mathrm{k}$ forms various unrelated syntactic relations in the syntax. Modifiers may be coindexed with a little $\mathrm{v}$ in the noun incorporation construction (see Johns 2003), as in (4) above. It is also found as the extra case assigner in a ditransitive construction, as in (3) above. Finally, it appears on "objects" in the antipassive construction. Little $\mathrm{k}$ forms a syntactic relation with little $\mathrm{v}$, which I will characterize as AGREE.

This idea is similar to that proposed in Svenonius (2001). Based on the proposal of Pesetsky and Torrego (2001) that nominative case is uninterpretable tense, Svenonius (2001) posits that structural case in Icelandic is the manifestation on the NP of semantically interpretable features within the VP. Svenonius proposes to remove the case feature from its anomalous category as the only feature of the syntactic component which is always uninterpretable. He proposes instead that accusative case is an uninterpretable feature which is checked by an interpretable feature. Effectively, in the framework of Chomsky (2000), we may view accusative/partitive case as an AGREE relation. I will assume some version of such an analysis here, and now turn in the next section to a discussion of the interpretable features which are present in little $\mathrm{v}$.

\section{Aspect and Antipassive}

when there is $3 / 3$, i.e. when both the agent and the theme are third person. 
Aspect has been a constant topic within the discussion of antipassive in Inuktitut (see Bittner 1987; Benua 1995; Seigel 1997; Spreng 2001 and this volume) and with antipassive crosslinguistically (see Dixon 1994).

In recent years, a number of linguists have focussed attention on the pivotal relation between aspect and case in some languages. In fact, Kiparsky (1998), a paper on Finnish aspect case relations, inspired Svenonius (2001) to claim that case can be instantiated aspect. The interplay between Finnish partitive and aspect is shown in (6). The data and analysis are taken from Kiparsky (1998), although the presentation is modified.

(6) a. Ammu-i-n karhu-a shoot-past-1s bear-Partitive 'I shot at the/a bear'

b. Ammu-i-n karhu-n shoot-past-1s bear-Accusative 'I shot the/a bear'

c. saa-n karhu-j-a get-1s bear-plural-Partitive 'I'll get bears'

d. saa-n karhu-t get-1s bear-Accusative 
'I'll get the bears'

The partitive case can reflect the unboundedness or either the verb or the noun, depending on the inherent aspect of the verb. In (6a) it reflects the unboundedness of the predicate because the verb 'shoot' can be either unbounded or bounded. When the predicate is bounded, accusative case is found on the nominal, as in (6b). In (6c), verb 'get' is inherently bounded. As a result, the partitive case can only reflect the unboundedness of the nominal, i.e. a canonical partitive meaning. When the nominal is itself bounded, accusative case is found, as in (6d). If a verb is inherently unbounded, only partitive case will be found on the object, regardless of whether the object itself is bounded or not.

Similarly, Scots Gaelic displays differential case marking on the object, depending on the aspect of the verb. The data is from Ramchand (1997, 89-90).

(7) a. Bha Calum a'gearradh chraobhan be-past Calum ag cut-Vnoun trees-gen 'Calum was cutting trees'

b. Gheàrr Calum craobhan cut-past Calum trees-DIR 'Calum cut some particular trees'

c. Tha Calum a'gearradh na craoibhe be-pres Calum ag cut-vnoun the tree-gen 
'Calum is cutting/cuts at the tree'

In particular we see that in (7c), where the NP is definite, the morphological genitive is not associated with an indefinite reading, as it is in (7a), but instead marks the unboundedness of the entire predicate.

What we learn from these two cases then is that it is possible for a syntactic relation to exist between aspect within the predicate/VP and case on the nominal, such that the case on the nominal is sometimes the morphological reflex of predicate aspect.

\subsection{Relation Between Aspect and Antipassive in Inuktitut}

The connection between the Inuktitut antipassive and aspect has been discussed at least since Bittner (1987), who mentions, in her cogent discussion of general meaning differences between the ergative and antipassive clause, that many of the antipassive morphemes mark aspect. Benua (1995; 2001), recognizing the similarity between the Finnish and Scots Gaelic cases, and Eskimo languages, develops an aspectual analysis based on Yup'ik, a language closely related to Inuktitut. Following Borer (1993), Benua proposes that aspect forms an ASP phrase above the VP and that absolutive objects move outside of this phrase, while antipassive objects remain within it. Predicates and some NPs remaining within the ASPP headed by the antipassive will get an incomplete aspectual interpretation. A Yup'ik example illustrating this distinction is shown in (8). ${ }^{10}$

\footnotetext{
${ }^{10}$ We note that names seem to be possible with MIK in Yup'ik. Thus Yup'ik, although a western language within the Eskimo language family, is distinct from western dialects of
} 

(8) a. Lucy-m Mary-q
utaqallrua
[Benua 1995, 37]
Lucy-erg Mary-abs wait.for-past-3s/3s
'Lucy waited for Mary'

b. Lucy-q Mary-mek utaqallruuq

$$
\text { Lucy-abs Mary-MIK wait.for-past-3s }
$$

'Lucy waited for Mary'

\begin{abstract}
According to Benua, Mary is assumed to have showed up in (8a), but did not necessarily appear in (8b).

Spreng (2001) investigates this issue in Mittimatalik, an eastern dialect of Inuktitut spoken on Baffin Island. She does not find significant differences in interpretation.
\end{abstract}

(9) a. Luci-up Mary utarqi-laur-tanga [Spreng 2001, 162]

Lucy-rel. Mary(abs) wait.for-past-3s/3s

'Lucy waited for Mary' (no sense as to whether Mary showed up)

b. Lucy utarqi-laur-tuq Mary-mik

Lucy wait.past.3s Mary-MIK

'Lucy waited for Mary' (Mary probably showed up)

Inuktitut. However Yup'ik has collapsed MIK case with another case MIT, so it is a 
More importantly, Spreng (2001) delineates between two functions of "antipassive" morphemes within Inuktitut. One of the most common antipassive morphemes across dialects is $-s i,{ }^{11}$ which can appear both as an unambiguous inceptive aspectual marker, as in (10a), or more ambiguously, as an antipassive morpheme, in (10b).

(10) a. Peter pisu-si-juq

Mittimatalik [Spreng 2001, 170-171]

Peter walk-incept-intr.3s

'Peter starts to walk'

b. Peter surak-si-juq anautar-mik

Peter-break-AP-intr.3s stick-MIK

'Peter broke the stick.'

Spreng makes an important and strong argument for not conflating these two usages. First of all, the meanings are very different. The genuine antipassive does not have an inceptive meaning, i.e. (10b) does not mean 'Peter is starting to break the stick.' Secondly the genuine antipassive morpheme is syntactically obligatory when it is found (its appearance depending on the argument structure of the verb). In contrast, the inceptive morpheme is always syntactically optional whenever it is found. Thirdly, the inceptive morpheme displays slightly different phonological properties in Mittimatalik, deleting any stem final consonant. The antipassive morpheme does not trigger this deletion. This

slightly different system (see Mather, Meade and Miyaoka 2002). 
property can be seen in (10a) where the verb pisuk 'walk' has undergone deletion. In contrast, in (10b), the verb surak ${ }^{12}$ 'break' does not undergo deletion. Keeping these two usages distinct is critical to understanding the antipassive, as Spreng (this volume) shows for Iñupiaq. She provides evidence that a) the genuine antipassive morpheme is merged in little $\mathrm{v}$ and $\mathrm{b}$ ) that inceptive aspect is not in this position. Thus antipassive and aspect morphemes are in distinct syntactic positions.

\subsection{A Proposal}

While accepting Spreng's analysis of antipassive morphology as being little v, I will depart from her conclusion that the inceptive morpheme and the antipassive morpheme are not related. ${ }^{13}$ Instead I propose that they both contain the same features, those of an indefinite quantifier. When these features are located outside the VP, they are interpreted as inceptive aspect. Within the VP, while they maintain aspectual features, they are simply atelic. Most importantly, from their position in little $\mathrm{v}$, they form a link with accusative case.

Interestingly, Travis (forthcoming) also discusses aspectual morphemes in Tagalog which can have either +start or imperfective interpretations. The former is outer aspect in Travis' analysis and the latter is inner aspect. These correspond remarkably with Spreng's analysis of Inuktitut $-s i$, where the inceptive is outside the VP and the

${ }^{11}$ Johns $(1999 ; 2001)$ claims that there is a paucity of antipassive morphemes in western dialects of Inuktitut, as compared with eastern ones. Nagai (personal communication) corrects this view, showing that that there are at least four in Iñupiaq (see Nagai 1998).

${ }^{12}$ The root here is normally suraq- in other dialects.

${ }^{13}$ Siegel (1998) also broaches the issue of the homophony of the aspectual and antipassive uses of - si. Like Spreng (2001), she realizes that the distributions of the two 
antipassive morpheme is in little v. The main difference between Tagalog and Inuktitut is that in the former, inner and outer aspect are spelled out as different morphemes, while in Inuktitut the same phonological material can be inserted in each position. Travis argues for both a non-derived and derived object position, where the derived position is licensed by aspect. Inuktitut has only the derived position within the VP for objects. Thus Inuktitut in general lacks canonical, or non-derived, accusative case.

When the indefinite quantity features are outside of the vP, they are interpreted as indefinite activity external or peripheral with respect to the event or action. When they are merged in the little v position, these same atelic features result in imperfective or indefinite boundary with respect to the event. In little v position. these features, which are interpretable, can form an agreement relation with little $\mathrm{k}$. Under this view, little $\mathrm{k}$ has uninterpretable features, following the proposal of Svenonius (2001) for Icelandic. Thus the representation for the MIK case is shown in (11).

(11) MIK-case

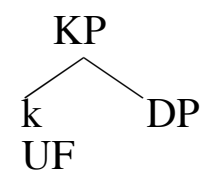

However, unlike most uninterpretable features, these are quite unspecified as to the category they are seeking to agree with, i.e. they have no Match properties. ${ }^{14}$ In the

basic meanings are complementary, but she stops short of providing an account in which the same features are involved.

${ }^{14}$ Susana Bejar has suggested to me (personal communication) that such a probe resembles EPP features. 
antipassive, these features form an AGREE relation ${ }^{15}$ with the interpretable aspectual features in little $\mathrm{v}$, as shown in (12). ${ }^{16}$

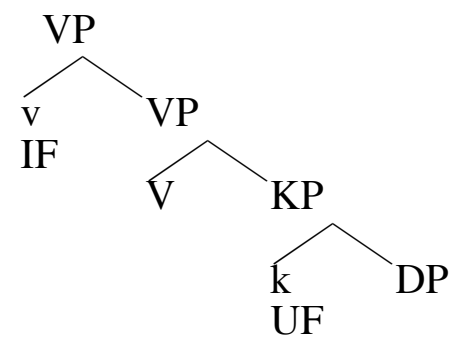

The AGREE relation between the uninterpretable features of the default case MIK and the interpretable features of the aspectual morpheme when it appears in little v explains a number of properties of Inuktitut. First of all it explains why the antipassive morphemes are homophonous with aspectual morphemes, at the same time allowing them distinct properties. They are not the same "morphemes." What they are is the same features in different positions of the syntactic tree. This conclusion is in keeping with tenets of Distributed Morphology. Halle and Marantz (1993) claim that morphemes do not exist per se, but that syntactic features are spelled out through phonology. An analysis which rejects the premise that the aspect and antipassive morphemes contain the same features, e.g. Spreng (2001), will have no explanation for the frequent, but not necessary, homophony across aspect and antipassive in Inuktitut. On the other hand, an analysis

\footnotetext{
${ }^{15}$ Note that the uninterpretable features will have to probe upwards in order to be satisfied. This seems possible under an interpretation of AGREE as involving dynamic search space - see Rezac 2004.

${ }^{16}$ In the antipassive construction, an antipassive morpheme must occupy little v. If one were missing, the uninterpretable features could look higher. In fact, the reflexive construction consists of a pronoun marked with MIK, an intransitive verb and no antipassive morpheme.
} 
which holds that the aspect/antipassive pairs are exactly the same morpheme will have no explanation for the varying interpretations, and varying obligatory properties.

Another outcome of this relation is an explanation for the indefinite nature of the NP-MIK in many dialects of Inuktitut. Since the features with which the NP-MIK has an agreement relation are indefinite quantity, we get an indefinite or partitive meaning for the nominal. When the nominal is a name, the name and indefinite features clash. As a result, names are impossible in these dialects with MIK case, except where the name is interpreted as some abstract property.

The fact that the same features are involved, but in different positions, predicts that the genuine aspect morpheme will be optional, as would be expected of an inceptive, but that the antipassive morpheme is obligatory in contexts where little v must be filled (see Spreng 2001). It also explains the difference in interpretation of antipassive vs. ergative clauses. Benua $(1995 ; 2001)$ discusses how an antipassive morpheme is translated as ongoing, or incomplete in some sense, while the ergative clause is not. Yet this aspectual interpretation is not identical to the "pure" aspect interpretation of the morpheme outside of little v. While this latter interpretation is inceptive, the antipassive morpheme is imperfective, ongoing, unbounded, atelic, etc.

Finally, this approach explains, as Spreng (2001) demonstrates, the presence of both aspectual and antipassive morphemes on the same verb, as in (13).

(13) anguti kunik-si-si-vuq arna-mik ${ }^{17}$ Mittimatalik [Spreng 2001, 165] man kiss-AP-Incept-3s woman-MIK 
'The man is starting to kiss the woman'

In (13) we have both morphemes, where the same features are both in little v and above VP. Spreng argues that the inceptive is outside the antipassive based on the fact that only the aspectual morpheme deletes stem final consonants, and the stem kunik- does not undergo consonant deletion. Under the current approach, the deletion of phonological material will not result from the features of the morpheme, but from the position of the features. Spreng's analysis is supported by the fact that the deletion of the second $-s i$ will result in the loss of inceptive interpretation of the verb.

Positing indefinite quantifier features on antipassive morphemes is in keeping with analyses that link aspect to antipassive (Bittner 1987; Benua 1995, etc.). It also predicts that where a language makes an aspectual split between seemingly nominativeaccusative and ergative-absolutive properties, that the nominative-accusative, and not the ergative-absolutive, will be associated with the imperfective.

\subsubsection{No Null Antipassive}

Spreng (2001; this volume) argues that in Inuktitut, an overt antipassive morpheme is in little $\mathrm{v}$ in causative verbs, i.e. when the verb is inherently causative, e.g. kapi- 'stab,' as in (14a) below. Overt antipassive is also found in the little $\mathrm{v}$ of derived causative verbs, which alternates with an unaccusative, as in (14b) below. Spreng argues, against all previous analyses, that there is no reason to posit a zero allomorph for the antipassive. She proposes that the presence of an overt antipassive morpheme such as $-s i$ in these

\footnotetext{
${ }^{17}$ Based on other dialects, this form should be arnar-mik. or arnang-mik. It may be that
} 
verbs is blocked by the fact that both unergative and object-deletion verbs, the root $\sqrt{ }$ incorporates into little $\mathrm{v}$ position. The distribution of antipassive morphology is shown in the Mittimatalik examples in (14), all from Spreng (2001).

a. Peter kapi-si-vuq nanu-mik ${ }^{18}$

Peter stab-AP-3s polar.bear-MIK

'Peter stabbed a polar bear'

b. Peter maturi-si-juq paa-mik

Peter(abs) open-AP-3s door-MIK

'Peter opens a door'

c. anguti niri-juq niqi-mik

$\operatorname{man}(\mathrm{abs}) \quad$ eat-3s meat-MIK

'The man is eating meat.'

Thus Spreng explains the fact that not all antipassive constructions in Inuktitut manifest antipassive morphology. From the perspective taken in this paper, Spreng's results fit in well. Recall that an overt antipassive morpheme is associated with an indefinite quantity feature in little v. We find a parallel in verb roots which are inherently atelic, or unbounded, i.e. activity predicates. These are the only verb roots which move to little $\mathrm{v}$ in this construction. In fact, as Spreng shows, the addition of antipassive morphology to 
these predicates will inevitably result in a "genuine" aspectual interpretation, i.e.

inceptive, as in (10a) above. The explanation for this is that the activity roots occupy little $\mathrm{v}$, so the only position the "antipassive" morpheme can merge in is external to the vP, i.e. it will never have the properties of antipassive morpheme, only those of an aspectual morpheme and is therefore grammatically optional. Thus the distribution of overt antipassive morphemes in an antipassive construction is conditioned by the aspectual nature of the verb root; those verb roots which are inherently atelic do not take an antipassive morpheme, and those which are not inherently atelic need an aspect morpheme occupying little $\mathrm{v}$ in the antipassive construction. In addition, the dual nature of the aspectual morpheme as both atelic and antipassive is clarified. Where it merges in little $\mathrm{v}$, it is antipassive and obligatory in that construction; elsewhere it is aspectual and found optionally.

\subsection{Multiple Antipassives in Other Languages?}

Gerdts and Hukurai (2000), in a stimulating paper about antipassives in Halkomelem, point out that Halkomelem antipassive morphemes are aspectual in meaning, the most common one - els having the meaning of "a job-like activity." They show that this morpheme, along with another antipassive morpheme which they call the middle suffix $(-m)$, can appear stacked, as it were, on a single verb. This can be seen in (15), where the antipassive morpheme $-m$ is followed by $-e l s$ (both shown in bold).

$$
\begin{aligned}
& \text { q'wəl-əm-els cən ce? ?ə_w sce:Itən ?ə_kweyəl-əs } \\
& \text { bake-mid-act } 1 \text { sub fut obl det salmon comp day-3ssub }
\end{aligned}
$$

\footnotetext{
${ }^{18}$ Again other dialects would have nanurmik or nanungmik. See footnote 17.
} 
'I am going to barbeque fish tomorrow.' [Gerdts and Hukari 2000] For Gerdts and Hukari, both -els and $-m$ are antipassive morphemes. They describe examples such as (15) as posing a problem for linguistic theory. If an antipassive morpheme detransitivizes a transitive verb, as is conventionally assumed, then how can there be a second antipassive morpheme? Following the first antipassive morpheme, there would be nothing left to detransitivize. They argue that the existence of stacked antipassives is evidence against a demotion analysis of antipassives in favour of a mapping analysis where the object is "not linked" twice.

We have just seen similar examples in Inuktitut. Above, we saw that Spreng (2001) argues that only one of the pair of antipassives in (13) above is truly an antipassive, i.e. is in little v. Thus we may hypothesize that the Halkomelem example in (15) is of the same nature, one antipassive morpheme in little $v$, followed by one aspectual morpheme. If this is so, we expect that the meaning of the second antipassive morpheme in (15) above to be more genuinely aspectual than we would find when it is the only antipassive morpheme, as in the Halkomelem example in (16).

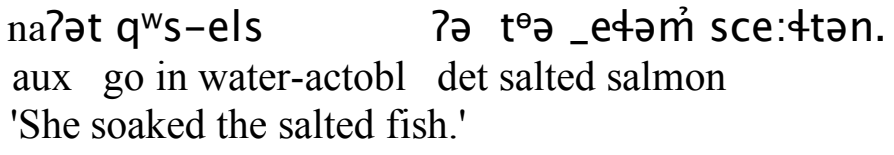

[from Gerdts and Hukari 2000]

The translation in (15), where -els is the second "antipassive" does not seem to have more aspectual meaning than (16), but it is difficult to tell without more examples. Evidence for an analysis along the lines of the one proposed in this paper would involve whether or not the "antipassive" morpheme -els can also be found on intransitive verbs, 
as is the case of -si in Inuktitut (see 10a above). If such is the case in Halkomelem, we would then investigate whether or not the "antipassive" is optional in both intransitives and double antipassive constructions. The assumption is that only one genuine antipassive morpheme is ever found in one construction, and it is obligatory. If it turns out that the Halkomelem facts resemble those of Inuktitut, then we may suppose that, like Inuktitut, aspect in Halkomelem will "grammaticalize" just when it is needed to merge in little v. When not in this syntactic position, it will modify the entire VP.

The data in Gerdts and Hukari (2000) does not contain evidence in either

direction. Thus we currently cannot determine if Halkomelem stacked antipassives are in fact an antipassive followed by aspectual marker.

\section{The MIK Case and Change Across Dialects}

We know return to the initial cross-dialectal differences outlined in section 2 . How can we explain the differences between the majority (or possibly just western) varieties of Inuktitut, and Labrador Inuttut (and perhaps all eastern dialects), where the latter shows more of a nominative-accusative pattern. The incremental nature of this change, as described in Johns (1999; 2001a, b) now become more clear. We are not simply switching from an ergative-absolutive system to a nominative-accusative system in one fell swoop. Johns (2001b) argues that the switch is from a lexical to a structural case. This turns out to be gross simplification. I propose here instead that the featural properties involved in the case agreement relation between the verb and the nominal have changed. In the more conservative western dialects, the AGREE relation is based on a relation between the content of little $\mathrm{v}$ and uninterpretable features of the MIK case on 
the nominal. In contrast, in Labrador Inuttut, the relation has changed from agreeing with the content of little $\mathrm{v}$ to a more formal agreement relation, bringing it closer to accusative case, as Bok- Bennema (1991) argues for all Inuktitut. In other words, the MIK case has changed from general uninterpretable features, as in (17a) to one with a Match property, needing to match with the category $\mathrm{v}$, as in (17b). ${ }^{19}$

(17) a. Western Dialects

\begin{tabular}{|lll}
$\mathrm{ASP}(\mathrm{F})$ & $\mathrm{UF}$ \\
$\mathrm{MIK}$ & No Match Properties
\end{tabular}

b. Labrador Inuttut

$\mathrm{ASP}(\mathrm{F}) \mathrm{v} \quad \mathrm{UF}_{\mathrm{V}} \mathrm{MIK} \quad$ Match Properties

The Uninterpretable Features (UF) in (17a) are very broad and are consistent with MIK being a Default Case (see Schütze 2001). Legate (this volume) proposes that absolutive in Warlpiri is a Default Morphological Case, meaning that when a particular case is licensed, but lacks phonological form, the default absolutive will be inserted. In contrast, MIK is a Default Syntactic Case. It is not associated with a specific case licenser. Crucially, as Schütze (2001) argues, Default Case is not freely generated, but is found in a set of constructions which resemble the elsewhere class, not having a common factor.

The default MIK case has UF. As a result, it must link with some element, which although it is not a canonical Case Licenser, will be able to satisfy the uninterpretable features of MIK. Through this linking, Case is satisfied. MIK is found in many different contexts in these dialects. In the antipassive construction, MIK forms the relation AGREE with the morpheme in little v (i.e. antipassive morpheme or activity verb. Thus

\footnotetext{
${ }^{19}$ Something of this nature must be a property of language; otherwise all languages
} 
the uninterpretable features of MIK will be eliminated as they link to the interpretable aspect features of little v (à la Svenonius 2001). As a result of the indefinite quantity interpretation of the atelic aspect in little v, the nominal to which MIK attaches will also be interpreted as an indefinite quantity, something like partitive. Names will not normally be possible in this context.

However, there are other features which can also satisfy the UF of MIK. If the KP containing MIK is adjoined to the $\mathrm{vP}$, an AGREE relation can be established with the agent of the clause, leading to an instrumental interpretation. This is shown in (17).

(18) a. Inuvialuktun Lowe (1985b, 63)

tukingayu-mik qupi-yaa

axe-MIK split-3s/3s

'He split it with an axe.'

b. Uummarmiut Iñupiaq Lowe (1985a, 64)

angalat-kaa aluutta-mik

stir-3s/3s spoon-MIK

'She stirred it with a spoon'

As mentioned in section 1., one of the names for the MIK case is instrumental. We now see that the instrumental interpretation of MIK in (18) is derived from its "parasitic" nature, that is , it agrees with the first interpretive property it can find within its domain, ${ }^{20}$ the agent role. As an instrument is a subsidiary to the agent, the MIK case spells out this

would be like Finnish, agreeing in aspect with the verb. 
property. A prediction of this account is that, in western dialects, when MIK is instrumental case, names will not be prohibited. This is because MIK, in its instrumental realization, is not linked to aspect but merely to agency. This prediction turns out to be true, as can be seen in the following example from Iñupiaq [Lowe 1985a, 65]

$$
\text { Martha Kaapani-lia-qami Igluru-mik uqaqhi-huaq }
$$

Martha(abs) Bay-go-when3Reflexive Igluruq-MIK speak-3s

'When Martha went to the Bay, she used Igluruq as an interpreter.'

Returning to the representation for MIK case in Labrador Inuttut in (17b), we see one main difference. In Labrador Inuttut, there is a MATCH property on MIK, which entails that it probes not for just the first interpretable feature it can find, as does the MIK in (17a); instead, it probes for the first little v category it can find. Again, the aspect in little $\mathrm{v}$, will satisfy the uninterpretable features of MIK; however this time the AGREE relation is formed with the category $\mathrm{v}$, not the atelic aspect. As a result, there is no concomitant partitive interpretation to nominal objects with MIK case. Names are allowed as MIK objects.

The change of MIK to an element with UF Match property has consequence for the instrumental case in Labrador Inuttut as well. Given that MIK in this dialect probes only for a $v$ Match, it is impossible for it to be parasitic on the semantic property agency in this dialect. We thus predict that MIK is unavailable for instrumental case in this dialect. This turns out to be true, as shown in (20).

(20) Labrador Inuttut [Smith 1977, 20]

${ }^{20}$ Clearly more must be said about uninterpretable case features and domains. Unlike features of $\mathrm{T}$ and $\mathrm{C}$, uninterpretable features of $\mathrm{K}$ seem to look only upwards and not downwards. This may have something to do with nature and structure of case. 
sana-sima-juk savi-mmut

work-complete-3s knife-MUT

'He made (it) with a knife'

In fact the instrumental case is also MUT in the Tarramiut dialect of Inuktitut spoken in northern Québec, as shown in (21), taken from Dorais $(1988,31)$.

(21) kautar-nut sana-jau-juq

hammer-MUTpl. work-passive-3s

'With hammers, it has been worked'

In neither Labrador nor Quebec grammars of Inuktitut is there any mention of an instrumental meaning associated with MIK. Conversely there is no mention of an instrumental use of MUT in the grammars of the two western dialects in (17). Thus the choice of instrumental case marking may be a signal of a grammatical boundary or isogloss between dialects. Dialects A) use MIK as an instrumental and have an obligatory indefinite/partitive interpretation on objects of antipassives. Dialects B) use MUT as an instrumental and do not restrict the interpretation of objects of the antipassive.

A more general question then arises: is there any difference in interpretation in Labrador Inuttut between the theme/patient in absolutive case in an ergative construction and the theme/patient in MIK case in the antipassive construction? It is likely that there is none in Labrador Inuttut, and this has likely led to the (near) eradication of the ergative construction, in main clauses.

While the use of MIK versus MUT for the instrumental is very telling, there remain many questions regarding dialect differences. For example, the link between 
widespread use of ditransitive constructions and strong ergativity requires further research.

\section{Conclusion}

We have seen that a number of results derived from combing the aspectual analysis of Bittner (1987), Benua (1995), etc. with the little v analysis of Spreng (2001). It turns out that aspect is part of the VP, except that, when it heads little v, it is no longer only an aspectual element but also a "case assigner" in the sense that it is in a syntactic position which can satisfy the uninterpretable features of the case feature in light k. Homophony with actual aspect markers, complementary distribution with unergative roots, and meaning variation all derive from this distinction.

We can now understand that by characterizing the case/little $\mathrm{v}$ relation as AGREE, why the antipassive in Inuktitut looks to be intransitive. Lack of person and number agreement with theme/patient in an antipassive is a direct result of the fact that it agrees with other features. Likewise the interpretation of theme/patients as quantitative entities results from this agreement relation. Thus antipassive not really a detransitivizing process but another type of transitive.

Change in ergativity in Inuktitut is now seen to be related to extent to which Default Case contains a Match feature. In the more ergative dialects the Match feature is missing, thus the Default Case is found in a wide variety of syntactic contexts. In the dialect with less ergativity, there is a Match feature, restricting the syntactic contexts of the Default Case and bringing it closer in line to accusative case in more familiar languages. 


\section{References}

Beach, M. 2003. Asymmetries between Passivization and Antipassivization in the Tarramiutut Subdialect of Inuktitut. Paper presented at the 2003 Lexical Functional Grammar Conference July 2003, Saratoga Springs.

Benua, L. 1995. Yup'ik Antipassives. CLS Proceedings, 28-44.

Benua, L. 2001. Yup'ik Antipassive and the AspP Hypothesis. UMOP 20, 107-138. GLSA, Department of Linguistics, University of Massachusetts at Amherst.

Bittner, M. 1987. On the Semantics of the Greenlandic Antipassive and Related Constructions. International Journal of American Linguistics 53, 194-231.

Bittner, M. and K. Hale. 1996a.The Structural Determination of Case and Agreement. Linguistic Inquiry 27, 1-68.

Bittner, M. and K. Hale. 1996b. Ergativity: Towards a Theory of Heterogenous Class. Linguistic Inquiry 27, 531-604.

Bok-Bennema. 1991. Case and Agreement in Inuit. Dordrecht: Foris Publications.

Dixon, R. M. W. Ergativity. Cambridge Studies in Linguistics 69. Cambridge: Cambridge University Press.

Borer, H. 1993.The Projection of Arguments. University of Massachusetts Occasional Papers in Linguistics 17, 19-47.

Compton, Richard. 2004. On Quantifiers and Bare Nouns in Inuktitut. Toronto Working Papers in Linguistics 23.1, 1-45.

Dorais, L.-J. 1988. Tukilik: An Inuktitut Grammar for All. Inuksiutiit Katimajiit, GETIC, Université Laval. 
Chomsky, N. 2000. Minimalist Inquiries: The Framework. In R. Martin, D. Michaels and J. Uriagereka, Step by step. Essays on Minimalist Syntax in Honor of Howard Lasnik, 89-155. Cambridge: MIT Press.

Gerdts, D. and T. Hukari. 2000. Multiple Antipasssives in Halkomelem Salish. Proceedings of the 26 Meeting of the Berkeley Linguistics Society, Berkeley California..

de Hoop, H. 2003. Partivity. In Cheng, L. and R. Sybesma, eds., The Second Glot International State-of-the-Article Book.. Mouton de Gruyter, 179-212.

Halle, M. and A. Marantz. 1993. Distributed Morphology and the Pieces of Inflection. In K. Hale and S. J. Keyser, eds. The View from Building 20: Essays in Honor of Sylvain Bromberger, 111-176. Cambridge: MIT Press.

Johns, A. 2003. Restricting Noun Incorporation, ms. University of Toronto.

Johns, A. 2001a. Ergative to Accusative: Comparing Evidence from Inuktitut. In J. T. Faarlund, ed, Grammatical Relations in Change, 205-221. Amsterdam: John Benjamins.

Johns, A. 2001b. An Inclination Towards Accusative. Linguistica Atlantica, 127-144.

Johns, A. 2000. Ergativity: A Perspective on Recent Work. The First Glot International State-of-the Article Book, eds. L. Cheng and R. Sybesma, 47-73. Berlin: Mouton de Gruyter.

Johns, A. 1999. The Decline of Ergativity in Labrador Inuttut. Papers from the Workshop on Structure and Constituency in Native American Languages. MITWPL 17, 73-90.

Johns, A. 1992. Deriving Ergativity. Linguistic Inquiry 23, 57-87. 
Kiparsky, P. 1998. Partitive Case and Aspect. In M. Butt and W. Geuder, eds. The Projection of Arguments: Lexical and Compositional Factors, 265-307. Stanford: CSLI.

Legate, J. (this volume). Split Absolutive.

Lowe, R. 1985a. Uummarmiut Uqalungiha Ilihaurrutikrangit/ Basic Uummarmiut Eskimo Grammar. Committee for Original Peoples Entitlement.

Lowe, R. 1985b. Siglit Inuvialuit Uqausiita Ilisarviksait/ Basic Siglit Inuvialuit Eskimo Grammar. Committee for Original Peoples Entitlement.

Manning, C. 1996. Ergativity: Argument Structure and Grammatical Relations. Stanford: CSLI Publications.

Mather, E., M. Meade and O. Miyaoka. 2002. Survey of Yup'ik Grammar Revised. Endangered Languages of the Pacific Rim A2-23. Kyoto

Nagai, T. (1998) The Oblique Case in the Three-place Antipassive Construction in Upper Kobuk Iñupiaq. M.A. thesis, University of Tokyo.

Pesetsky, D. and E. Torrego. 2001. T-to-C Movement: Causes and Consequences. In D. Michaels, ed. Ken Hale: A Life in Language, 355-426. Cambridge: MIT Press. Ramchand, G. 1997. Aspect and Predication. Oxford University Press, New York.

Rezac, M. 2004 Elements of Cyclic Syntax: $\phi$-Agreement, Case and A-chains. Ph.D. Dissertation in progress, University of Toronto.

Schütze, C. 2001. On the Nature of Default Case. Syntax 4(3), 205-238.

Seigel, L. 1997. Argument Structure and Antipassivization in Inuit. Papers from the Penn/MIT Round-table on Aspect and Argument Structure, MITWPL 32. 
Seiler, W. 1978. The Modalis Case in Iñupiaq. Giessener Beiträge zur Sprachwissenschaft. Hoffman-Verlag Grossen-Linden.

Smith, L. 1977. Some Grammatical Aspects of Labrador Inuttut. National Museums of Canada (now Museum of Civilization) Mercury Series No. 37. [out of print]

Spreng, B. 2001. Little v in Inuktitut: Antipassive Revisited. Linguistica Atlantica, 155190.

Spreng, B. (this volume) Antipassive Morphology and Case Assignment in Inuktitut.

Svenonius, P. 2001. Case and Event Structure. In ZAS Working Paper 26.

Travis, L. (forthcoming) Inner Aspect. Kluwer.

Vainikka, A. 1989. Deriving Syntactic Representations in Finnish. Ph.D. dissertation, University of Massachusetts at Amherst.

Van Geenhoven, V. 1998. Semantic Incorporation and Indefinite Descriptions. Dissertations in Linguistics. Stanford: CSLI Publications.

Wharram, D. 2003. On the Interpretation of (Un)Certain Indefinites in Inuktitut and Related Languages. Ph.D. dissertation, University of Connecticut. 